\title{
Resenhando o debate sobre justiça ambiental: produção teórica, breve acervo de casos e criação da rede brasileira de justiça ambiental
}

\section{Redesigning the debate about environmental justice: theoretical production, a short list of cases and the creation of a Brasilian network of environmental justice}

\author{
Selene HERCULANO*
}

\section{Introdução}

O objetivo desta resenha é apresentar e divulgar entre nós uma linha de pesquisa e de ação no campo do Ambientalismo e da Sociologia Ambiental, que busca analisar, pela perspectiva das hierarquias sociais, vale dizer, das desigualdades de classe, a problemática da poluição ambiental e das conseqüentes ameaças à saúde coletiva de populações vulnerabilizadas. Para dar conta deste objetivo, indicamos as origens do conceito de Justiça Ambiental e, a seguir, apresentamos os esforços de pesquisadores e de ativistas ambientais brasileiros para adaptar à nossa realidade e encorajar entre nós o uso desta perspectiva. Finalmente, mostramos como estes esforços desembocaram na realização do Colóquio Internacional sobre Justiça Ambiental, Trabalho e Cidadania, realizado na Universidade Federal Fluminense, em Niterói, em setembro de 2001, quando se criou a Rede Brasileira de Justiça Ambiental - RBJA - e se redigiu a sua declaração de lançamento, aqui transcrita. Com esta resenha, esperamos divulgar a existência da RBJA e encorajar os leitores a dela virem participar.

\section{O que é Justiça Ambiental ${ }^{1}$}

Por Justiça Ambiental entenda-se o conjunto de princípios que asseguram que nenhum grupo de pessoas, sejam grupos étnicos, raciais ou de classe, suporte uma parcela desproporcional das conseqüências ambientais negativas de operações econômicas, de políticas e programas federais, estaduais e locais, bem como resultantes da ausência ou omissão de tais políticas.

Complementarmente, entende-se por Injustiça Ambiental o mecanismo pelo qual sociedades desiguais destinam a maior carga dos danos ambientais do desenvolvimento a grupos sociais de trabalhadores, populações de baixa renda, grupos raciais discriminados, populações marginalizadas e mais vulneráveis.

O conceito de Justiça Ambiental vem da experiência inicial dos movimentos sociais dos Estados Unidos e do clamor dos seus cidadãos pobres e etnias socialmente discriminadas e vulnerabilizadas, quanto à sua maior exposição a riscos ambientais por habitarem nas vizinhanças de depósitos de lixos químicos e radioativos ou

- UFF/ICHF/GSO, <selench@ar.microlink.com.br>

1 Texto parcialmente extraido do panfleto de divulgaçào do colóqquio, de redaçào coletiva,com a participação também de llenri Acselrad, José Augusto Pádua, Jean Pierreleroy e Paulo Roberto Martins 
de indústrias com efluentes poluentes. Como definiu Robert Bullard, Justiça Ambiental é "a busca do tratamento justo e do envolvimento significativo de todas as pessoas, independentemente de sua raça, cor, origem ou renda no que diz respeito à elaboração, desenvolvimento, implementação e reforço de políticas, leis e regulações ambientais. Por tratamento justo entenda-se que nenhum grupo de pessoas, incluindo-se aí grupos étnicos, raciais ou de classe, deva suportar uma parcela desproporcional das consequiencias ambientais negativas resultantes de operações industriais, comerciais e municipais, da execução de políticas e programas federais, estaduais, locais ou tribais, bem como das conseqüências resultantes da ausência ou omissão destas políticas".

"Environmental justice is defined as the fair treatment and meaning ful involvement of all people regardless of race, color, national origin or income with respect to the development, implementation and enforcement of environmental laws, regulations and policies. Fair treatment means that no group of people. including racial, ethnic or socio-economic groups should bear a disproportionate share of negative environmental consequences resulting from industrial, municipal and commercial operations or the execution of federal, state. local and tribal programs and policies." (BULLARD, 2000, discurso na Mercer University')

No campo da formulação e implementação de mecanismos políticos, o movimento por justiça ambiental foi o influenciador de toda uma legislação norte-americana, como, por exemplo, a que diz respeito aos procedimentos para os clean-ups (descontaminação), a legislação sobre o direito à informação sobre o que existe ou existirá em uma dada vizinhança Right to know Act e a criação de fundos direcionados às comunidades afetadas, dando-lhes meios financeiros para contratar serviços técnicos e advocatícios. (DOWER, R. Hazardous Wastes; SAPIRO, M. Toxic Substances Policy, ambos em PORTNEY, P. R. Policies for environmental protection, Washington: Center for Risk Management at Resources for the Future/John Kopkins University Press, 1995, 5th edition. GiBBS, Lois M. Love Canal. 20th anniversary revised edition. Gabriola Island, New Society Publishers, 1998).

No meio acadêmico norte-americano, na área da Sociologia Ambiental, programas de pós-graduação e centros de estudo foram sendo criados:
- Environmental Justice Research Center - EJRC da Universidade de Atlanta, Geórgia;

- Deep South Center for Environmental Justice, na Xavier University na Louisiana;

- Environmental Justice Program da School of Natural Resources and Environment da Universidade de Michigan.

Uma ampla bibliografia discute a questão, como se pode ver na breve compilação bibliográfica inclusa no item Bibliografia sobre riscos desta revista.

\section{Ampliando a temática: incorporando no Brasil outras carências e iniqüidades}

A temática da Justiça Ambiental nos interessa face às extremas desigualdades da sociedade brasileira. No Brasil, país das grandes injustiças, o tema da justiça ambiental é ainda incipiente e de difícil compreensão, pois a primeira suposição é de que se trate de alguma vara especializada em disputas diversas sobre o meio ambiente. Os casos de exposição a riscos químicos são pouco conhecidos e divulgados, à exceção do estado de São Paulo, tendendo a se tornarem problemas crônicos, sem solução. Acrescente-se também que, dado ao nosso amplo leque de agudas desigualdades sociais, a exposição desigual aos riscos químicos fica aparentemente obscurecida e dissimulada pela extrema pobreza e as péssimas condições gerais de vida a ela associadas. Assim, ironicamente, as gigantescas injustiças sociais brasileiras encobrem e naturalizam o fato da exposição desigual à poluição e do ônus desigual dos custos do desenvolvimento.

Existe, no entanto, um conjunto de ações e movimentos sociais no país que podem ser identificados como de busca por "Justiça Ambiental", mesmo que sem o uso dessa expressão. É o caso do Movimento dos Atingidos por Barragens, dos movimentos de trabalhadores extrativistas resistindo contra o avanço das relações capitalistas nas fronteiras florestais e de inúmeras ações locais contra a contaminação e a degradação dos espaços de vida e trabalho.

No caso do Brasil, portanto, o potencial político do movimento pela justiça ambiental é enorme. O país é extremamente injusto em termos de distribuição de renda e acesso aos recursos naturais e sua elite governante tem sido especialmente egoísta e insensível, defenden- 
do de todas as formas os seus interesses e lucros, até lançando mão, em muitos casos, da ilegalidade e da violência. O sentido de cidadania e de direitos, por outro lado, ainda encontra um espaço relativamente pequeno na nossa sociedade, apesar da luta de tantos movimentos e pessoas em favor de um país mais justo e decente. Tudo isso se reflete no campo ambiental. O desprezo pelo espaço comum e pelo meio ambiente se confunde com o desprezo pelas pessoas e comunidades. Os vazamentos e acidentes na industria petrolífera e química, a morte de rios, lagos e baías, as doenças e mortes causadas pelo uso de agrotóxicos e outros poluentes, a expulsão das comunidades tradicionais pela destruição dos seus locais de vida e trabalho, tudo isso, e muito mais, configura uma situação constante de injustiça socioambiental no Brasil, que vai além da problemática de localização de depósitos de rejeitos químicos e de incineradores da experiência norte-americana.

$\mathrm{O}$ ambientalismo brasileiro, por outro lado, tem um grande potencial para se renovar e expandir o seu alcance social, à medida que se associe e se solidarize com as massas pobres e marginalizadas, que vêm se mobilizando em favor dos seus direitos. Os movimentos sindicais, sociais e populares, entre outros, também podem renovar e ampliar o alcance da sua luta se nela incorporarem a dimensão da justiça ambiental, o direito a uma vida digna e em um ambiente saudável. Todas essas lutas, na verdade, representam uma só e mesma luta pela democracia, pelo bem comum e pela sustentabilidade.

Assim, tendo em vista o maior grau de desigualdades e de injustiças socioeconômicas, bem como a renitente política de omissão e negligência no atendimento geral às necessidades das classes populares, a questão da justiça ambiental, para ser adequadamente equacionada entre nós, deve açambarcar também outros aspectos, tais como as carências de saneamento ambiental no meio urbano e a degradação das terras usadas para acolher os assentamentos de reforma agrária, no meio rural. Pois não são apenas os trabalhadores industriais e os moradores no entorno das fábricas aqueles que pagam, com sua saúde e suas vidas, os custos das externalidades da produção das riquezas brasileiras, mas também os moradores dos subúrbios e periferias urbanas, onde fica espalhado o lixo químico; os moradores das favelas desprovidas de esgotamento sanitário; os lavradores no campo, levados a consumir agrotóxicos que os envenenam; as populações tradicionais extrativistas, progressivamente expulsas de suas terras de uso comunal.

Por conta da vulnerabilidade destas populações e dado ao baixo grau de associativismo e de exercício de cidadania ainda presentes na cultura política brasileira, as iniciativas que convergem para a temática da Justiça Ambiental têm se desenvolvido mais através de movimentos ambientalistas formados por uma classe média de alta escolaridade e mais informada, alguns sindicatos profissionais, como os dos químicos e petroleiros, e comissões de meio ambiente de federações sindicais, do que por conta de movimentos de base e/ou coalizões de movimentos de cidadãos pobres afetados, como nos exemplos norte-americanos acima citados.

Alguns fatores genéricos e ideológicos têm contribuído para dificultar a percepção das injustiças ambientais, da distribuição desigual dos riscos ambientais entre países e entre classes sociais e etnias: 1) o produtivismo generalizado e também assumido pelo movimento operário; 2) o conservacionismo de uma corrente do movimento ambientalista que ignora as questões do universo da produção e que acredita que os problemas ambientais são "democráticos", por atingirem a todos, o que só é verdade a longo prazo quando, como lembrou o economista Keynes, "todos estaremos mortos"; 3) um pragmatismo imediatista que, ao destacar a reconhecida prioridade de se ter o que comer e onde se abrigar, acaba desqualificando as buscas por justiça ambiental e qualidade de vida e tornando-se um pensamento resignado. Para o movimento operário a questão do "dilema" entre preservação dos postos de trabalho e proteção ao meio ambiente sempre foi colocada como um limitador de suas ações. Assim, cria-se à força, pela cumplicidade involuntária dos trabalhadores, em nome da sua sobrevivência econômica, um quadro de injustiça crônica e de aceitação resignada das fatalidades ambientais.

Hoje, esta visão - ou trabalho ou ambiente limpo está sendo contestada e superada, segundo o sociólogo Paulo Martins, por trabalhos realizados fora e dentro do movimento sindical: o World Watch Institute, através de seu pesquisador Michael Renner, elaborou em setembro de 2000 o texto Working for the Environment: a Growing Sorce of Jobs, em que demonstra o quanto se pode gerar postos de trabalho através da redefinição de uma politica ambiental, do uso de energias alternativas, de novas formas de extração de recursos naturais, da 
ampliação da vida útil dos produtos, da ampliação dos serviços relativos a consertos desses produtos. Várias centrais sindicais vêm refletindo sobre esta questão, propondo novas formas de organizar a produção, novas tecnologias, que proporcionem elevado nível de uso da força de trabalho e preservação do meio ambiente. Este é o caso do trabalho organizado por Jorge Riechmann e Francisco Fernandes Buey, intitulado "Trabajar sin Destruir - Trabajadores, Sindicato y Ecologismo". Madrid, Ediciones Hoac, 1998.

No Brasil, o marco inicial de sistematização e divulgação da problemática referente à Justiça Ambiental foi a coleção intitulada "Sindicalismo e Justiça Ambiental", publicada em 2000 pela Central Única dos Trabalhadores - CUT/R.I, em conjunto com o Ibase, o Instituto de Pesquisas e Planejamento Urbano - IPPUR da UFRJ e com o apoio da Fundação Heinrich Böll. O intuito era "estimular a discussão sobre a responsabilidade e o papel dos trabalhadores e das suas entidades representativas, na defesa de um meio ambiente urbano sustentável e com qualidade de vida acessível a todos os seus moradores", dentro da "perspectiva de crítica ao modelo dominante de desenvolvimento" e entendendo que os "recursos ambientais são bens coletivos, cujos modos de apropriação e gestão são objeto de debate público". Também em 2000, o sociólogo Paulo Roberto Martins apresentava em um congresso um estudo em que descrevia casos de sindicatos que têm desenvolvido ações que indicam a institucionalização de uma luta por justiça ambiental, envolvendo tanto os trabalhadores e suas instituições representativas quanto os moradores do entorno das fábricas e os movimentos ambientalistas há por exemplo, o caso do Sindicato dos Químicos de São Paulo, na sua luta contra a Neclemom, empresa estatal pertencente a Nuclebrás e do Sindicato do Químicos do $A B C$ na sua luta contra a empresa Solvay, em São Paulo. Seu estudo contrastava os avanços ocorridos neste campo dentro da CUT com a compreensão ainda parcial que têm seus dirigentes a este respeito.

A temática da Justiça Ambiental também vem sendo elaborada em seus pontos de interseção com o estudo dos aspectos sociais da construção e usos da ciência e da tecnologia e do poder de definição das realidades por parte da comunidade científica e dos saberes juridicos. Isto implica na necessidade de: 1) articulação de uma ciência-cidadã que assessore a população (entre as ciências naturais, para o conhecimento dos riscos e dos efeitos das tecnologias de produção sobre a saúde humana; entre as ciências sociais, para que perceba a dimensão social e política presente na construção dos riscos e se organize em suas lutas); 2) da construção de uma cultura juridica aberta para dar acessibilidade a um Judiciário justo e operante.

Analisando esta interseção, apontamos nesta resenha não-exaustiva o livro de McAVOY, Controlling technocracy, citizen rationality and the $N T M B B$ syndrome, e a tese de doutoramento de Carlos Machado de Freitas intitulada "Acidentes químicos ampliados incorporando a dimensão social nas análises de riscos", apresentada à ENSP/FIOCRUZ, Rio, 1996.

\section{O Colóquio Internacional sobre Justiça Ambiental, Trabalho e Cidadania}

Para dar conta destas questões, o Colóquio Internacional sobre Justiça Ambiental, Trabalho e Cidadania, realizado na Universidade Federal Fluminense, em setembro de 2001, foi, senão a primeira, uma das primeiras iniciativas de cunho acadêmico e político a se organizar no Brasil, discutindo enfoques teóricos e implicações políticas da proposta de Justiça Ambiental; histórico e avaliação de campanhas e ações de cidadania; casos de injustiça ambiental no Brasil e na América Latina; trabalho e Justiça Ambiental na experiência dos sindicatos; reflexão política e construção de uma agenda; proposta de parcerias e de uma coalizão internacional.

Nele se reuniram os seguintes pesquisadores e ativistas: Robert Bullard, do Environmental Justice Research Center da Universidade de Atlanta - I:UA; Kenneth Gould, da St. Lawrence University - I:UA; Adeline Levine, da Universidade de Buffalo, LUA; Murray Levine, do Center for Health and Environmental Justice - CIIl.J, I:UA; Beverly Wright, do Deep South Center for Environmental Justice da Universidade Xavier da Louisiana; David Camacho, na Northern Arizona University; Cristina Hurtado, do Instituto de Ecologia Politica e da Rede Chile Sustentable; Carlos Surroca, do Uruguay Sustentable; Timmons Roberts, diretor do Mellon Program in Environmental Studies do College William and Mary; Henri Acselrad e Carlos Vainer, ambos da UlR.J/IPPUR; José Augusto Pádua, do Projeto Brasil Sustentável e Democrático; Selene Herculano, da UI: $\%$ Laboratório de Estudos de Cidadania, Territo- 
rialidade, Trabalho e Ambiente - Lactta; Jean Pierre Leroy, da Fase; Marcelo Firpo de Souza Porto e Carlos Machado de Freitas, ambos da Fiocruz; Eduardo Paes Machado, da UFBA; Carlos Bocuhy, da Campanha Billings te quero viva e conselheiro do Consema/SP; Paulo Roberto Martins, da Comissão de Meio Ambiente da CUT; João Carlos Gomes, da Associação dos Contaminados por Organoclorados - $\Lambda$ CPO); Fernanda Giannasi, da Rede Virtual Cidadã pelo Banimento do Amianto; Alfredo Wagner B. de Almeida, antropólogo; José Contreras Castillo, do Movimento em Defesa da Vida - MDV - do Grande ABC; Juvenil Nunes da Costa,do Sindicato dos Químicos do $A B C$, Marco Antônio Trierveiller e Sadi Baron, ambos do Movimento dos Atingidos por Barragens - MAB; Salvador Alves de Oliveira, do Sindicato dos Petroleiros de Caxias-RJ; Ney Santos Oliveira, da UFF e do Movimento Negro; Samuel Karajá, do Movimento Rios Vivos, Temístocles Marcelo Neto, da Diretoria da CUT, Edson Satochi Yamagawa, do Sindicato dos Petroleiros de Santos. Além destes palestrantes, a audiência reuniu cerca de 80 pessoas, de movimentos ambientalistas e sociais (Movimento de Ecologia Social Os Verdes, Roda Viva, Federação das Associações de Moradores de Niterói, Rede Brasileira de Florestas Rebraf, Sintravale, Ecocidade, Koinonia, Ibase, Instituto Gini Germani, de Buenos Aires), professores e alunos de programas de pós-graduação que trabalham a temática ambiental. (Em janeiro de 2002, novas adesões aconteceram durante o Fórum Mundial II em Porto Alegre).

Na ocasião, foi então criada a Rede Brasileira de Justiça Ambiental e redigida a declaração transcrita a seguir:

Declaração de lançamentos da rede brasileira de justiça ambiental

Representantes de movimentos sociais. sindicatos de trabalhadores, ONGs, entidades ambientalistas, organizaçoes de afrodescendentes, organizaçòes indigenas e pesquisadores universitários. do Brasil. Estados Unidos. Chile e Uruguai, reuniram-se no Colóquio Internacional sobre Justiça Ambiental. Trabalho e Cidadania, realizado em Niterói de 24 a 27 de setembro de 2001. Nessa ocasiào denunciaram e debateram a preocupante dimensào ambiental das desigualdades econômicas e sociais existentes nos países representados.

$\Lambda$ injustiça ambiental que caracteriza o modelo de desenvolvimento dominante no Brasil foi o loco das discussóes. Além das incertezas do descmprego, da desproteção social, da forma precária do trabalho, a maioria da população brasileira encontra-se hoje exposta a fortes riscos ambientais, seja nos locais de trabalho, de moradia ou no ambiente em que circula. Trabalhadores e população em geral estão expostos aos riscos decorrentes das substâncias perigosas, da falta de saneamento básico, de moradias $\mathrm{em}$ encostas perigosas e em beiras de cursos d'água sujeitos a enchentes, da proximidade de depósitos de lixo tóxico, ou vivendo sobre gasodutos ou sob linhas de transmissão de eletricidade. Os grupos sociais de menor renda, em geral, são os que têm menor acesso ao ar puro, à água potável, ao saneamento básico e à segurança fundiária. $\Lambda \mathrm{s}$ dinâmicas econômicas geram um processo de exclusão territorial e social, que nas cidades leva ao isolamento de grande massa de trabalhadores nas periferias e no campo, por falta de expectativa em obter methores condições de vida, leva ao êxodo para os grandes centros urbanos.

As populações tradicionais de extrativistas e pequenos produtores, que vivem nas regiòes da fronteira de expansão das atividades capitalistas, sofrem as pressões do deslocamento compulsório de suas áreas de moradia e trabalho, perdendo o acesso à terra, às matas e aos rios. sendo expulsas por grandes projetos hidrelétricos, viários ou de exploração mineral, madeireira e agropecuária. Ou então têm as suas atividades de sobrevivência ameaçadas pela definição pouco democrática e pouco participativa dos limites e das condições de uso de unidades de conservação.

Todas estas situações relletem um mesmo processo: a enorme concentração de poder na apropriação dos recursos ambientais que caracteriza a história do país. Uma concentração de poder que tem se revelado a principal responsável pelo que os movimentos sociais vêm chamando de injustiça ambiental. Entendemos por injustiça ambiental o mecanismo pelo qual sociedades desiguais, do ponto de vista cconômico e social, destinam a maior carga dos danos ambientais do desenvolvimento às populaçoes de baixa renda aos grupos raciais discriminados, aos povos étnicos tradicionais. aos bairros operários, às populaçòes marginalizadas e vulneráveis. Por justiça ambiental, ao contrário, designamos o conjunto de princípios e práticas que:

1) asseguram que nenhum grupo social, seja ele étnico. racial ou de classe, suporte uma parcela desproporcional das conseqüências ambientais negativas de operações econômicas, de decisões de políticas e de programas léderais. estaduais, locais, assim como da ausência ou omissão de tais políticas: 
2) asseguram acesso justo e eqüitativo, direto e indireto, aos recursos ambientais do país:

3 ) asseguram amplo acesso às informaçòes relevantes sobre o uso dos recursos ambientais e a destinação de rejeitos e localização de fontes de riscos ambientais. bem como processos democráticos e participativos na delinição de políticas, planos, programas e projetos que thes dizem respeito;

4) favorecem a constituição de sujeitos coletivos de direitos. movimentos sociais e organizaçòes populares para serem protagonistas na construção de modelos altemativos de desenvolvimento. que assegurem a democratização do acesso aos recursos ambientais c a sustentabilidade do seu uso.

listamos convencidos de que a injustiça ambiental resulta da lógica perversa de um sistema de produção, de ocupação do solo. de destruição de ecossistemas, de alocação espacial de processos poluentes, que penaliza as condições de saúde da população trabalhadora. moradora de bairros pobres exeluída pelos grandes projetos de desenvolvimento. Uma lógica que mantém grandes parcelas da população às margens das cidades e da cidadania, sem água potável, coleta adequada de lixo e tratamento de esgoto. Uma lógica que permite que grandes empresas lucrem com a imposição de riscos ambientais c sanitários aos grupos que. embora majoritários. por serem pobres, têm menos poder de se lazer ouvir na sociedade e, sobretudo. nas esferas do poder. Encpuanto as populações de maior renda têm meios de se destocar para áreas mais protegidas da degradação ambiental. as populações pobres são espacialmente segregadas, residindo em terrenos menos valorizados e geotecnicamente inseguros, utilizando-se de terras agrícolas que perderam fertilidade e antigas áreas industriais abandonadas. via de regra contaminadas por aterros tóxicos clandestinos.

Os trabalhadores urbanos e rurais, por sua ve\% estão freqüentemente submetidos aos riscos de tecnologias sujas. muitas delas proibidas nos paises mais industrializados, que disseminam contaminadores que se acumulam de maneira persistente no meio ambiente. Esses contaminadores, além de provocar doenças nos próprios trabalhadores, produzem "acidentes" por vezes fatais com crianças que circulam em áreas de periferia onde ocorrem os descartes clandestinos de resíduos. $A$ irresponsabilidade ambiental das empresas atinge $\mathrm{cm}$ primeiro lugar e com maior intensidade as mulheres, a quem cabe freqüentemente a lavagem dos uniformes de trabalho contaminados de seus maridos ou o manejo de recipientes de agrotóxico transformados em utensílios de cozinha. Esse ciclo de irresponsabilidade ambiental e social das empresas poluentes e de muitos gestores e órgãos governamentais. ameaça o conjunto dos setores sociais. haja visto que rios e alimentos contaminados por agrotóxicos e pela lalta de tratamento de esgoto acabam por aletar as populaçoes nas cidades.

A anencelalia nas crianças nascidas em Cubatão (SP). a presença das substâncias cancerígenas conhecidas como drins nas pequenas chácaras de Paulinia (SP). a estigmatização que perpetua o desemprego dos trabathadores contaminados por dioxina no $\triangle B C$ paulista. a alta incidencia de suicídio entre os trabalhadores rurais usuários de agrotóxicos em Venâncio Aires (RS) são exemplos que configuram as manilestaçoes visiveis de um modelo fundado na injustiça estrutural e na irresponsabilidade ambiental de empresas e governos. Apesar do fato de cue a lógica deste modelo é sistematicamente negada por seus responsáveis. que alegam a ausência de causal idade entre as decisoes politicas e produtivas e os eleitos danosos que lêm sobre suas vitimas. O enfrentamento deste modelo recuer que se deslaça a obscuridade e o silêncio que são lançados sobre a distribuição desigual dos riscos ambientais. $A$ denúncia dos mesmos. por outro lado, implica em desenvolver articuladamente as lutas ambientais e sociais: nào se trata de buscar o deslocamento espacial das práticas danosas para áreas onde a sociedade esteja menos organizada. mas sim de democratizar todas as decisòes relativas à localizaçào e às implicaçoos ambientais e sanitárias das práticas produtivas e dos grandes projetos economicos e de infraestrutura. Pensamos que o tema da justiça ambiental que indica a necessidade de trabalhar a questão do ambiente não apenas em termos de preservação. mas também de distribuiçào e justiça - representa o marco conceitual necessário para aproximar em uma mesma dinâmica as lutas populares pelos dircitos sociais e humanos e pelat qualidade de vida e a sustentabilidade ambiental. Por esse motivo criamos a Rede Brasileira de Justiça Ambiental, que tem os seguintes objetivos básicos:

1) Elaborar coletivamente uma "Declaração de Princípios da Justiça Ambiental no Brasil"

Essa declaraçào será objeto de um processo de discussão continuo de médio prazo. servindo para aglutinar forças. alinar conceitos e suscitar estratégias. Nos lUUA. o movimento de justiça ambiental loi estruturado nacionalmente a partir do programa dos"17 princípios" claborado em 1991, na Cúpula dos Povos de Cor pela Justiça 
Ambiental. No caso brasileiro. assim como naquele país. espera-se que um lal processo ajude a disseminar as lutas e as estratégias associadas à noção de justiça ambiental.

2) Criar um ou mais centros de referências de Justiça Ambiental

Trata-se de uma proposta de democratização de informaçós. criando bancos de dados que contenham registros de experiências de lutas. casos concretos de injustifa ambiental. conflitos judiciais, instrumentos institucionais etc. Trata-se também de aglutinar peritos de diferentes especialidades dispostos a apoiar as demandas de assessoria dos movimentos. Os centros ajudarào a acompanhar e divulgar resultados de pesquisa acadêmica sobre desigualdades ambientais. Fóruns periódicos debaterão e consolidarào as experiências dos diferentes tipos de lutas desenvolvidas.

\section{3) Diálogo permanente entre atores}

Promovero intercâmbio de experiências, idéias. dados e estratégias de ação entre os múltiplos atores de lutas ambientais: entidades ambientalistas. sindicatos urbanos a rurais. atingidos por barragem. movimento negro. remanescentes de quilombos. trabathadores sem terra. movimento de moradores. moradores em unidades de conservaçào, organizaçòes indígenas. ONGs. fóruns e redes. Além de encontros especílicos por setores. pretende-se organizar encontros maiores que ampliem a cooperação e o esforço comum de luta.

4) Desenvolvimento de instrumentos de promoção de justiça ambiental

Produzir metodologias de "Avaliação de leqüidade Ambiental". manuais de valorização das pereepçoes ambientais coletivas. mapeamento dos mecanismos decisórios com vistas à democratização das políticas ambientais em todos os niveis. cursos para a sensibilizaçào dos agentes do poder público envolvidos com a regulação do meio ambiente. Produzir argumentos conceituais a evidencias empiricas em favor da sustentabilidade democrática c da justiça ambiental.

5) Pressionar órgàos governamentais e empresas para que divulguem informaçòes ao público

Reivindicar a publicação sistemática de informaçòes sobre as fontes de risco ambiental no país. As agências estaduais, em particular, deverão ser pressionadas publicamente para produzir dados sobre a distribuição espacial dos depósitos de lixo tóxico e perigoso.
6) Contribuir para o estabelecimento de uma nova agenda de ciência e lecnologia

Apoiar pesquisas voltadas para os temas da justiça ambiental realizadas sempre que possivel através do diálogo entre pesquisadores. comunidades atingidas e movimentos organizados. Ajudar a formar técnicos e peritos que trabalhem dentro dessa perspectiva. Estimular o desenvolvimento de novas metodologias científicas e de novas tecnologias que ajudem a promover a luta contra a injustiça ambiental. sempre respeitando os direitos de cidadania e o saber das comunidades locais.

7) Estratégia de articulaçào internacional

Desenvolver contatos com parceiros internacionais no campo da estratégia política. da cooperação científica. da troca de informação sobre normas e padrós ambientais. da luta contra a exportação de processos poluentes e de depósitos de rejeitos perigosos. Preparar uma olicina sobre Justiça Ambiental no Il Fórum Social Mundial em Porto Alegre. 2002.

Consideramos que o termo Justiça Ambiental é um conceito aglutinador e mobilizador. por integrar as dimensòes ambiental. social e ética da sustentabilidade e do desenvolvimento. freqüentemente dissociados nos discursos e nas práticas. Tal conceito contribui para reverter a fiagmentação e o isolamento de vários movimentos sociais frente aos processos de globalização e reestruturação produtiva que provocam perda de soberania. desemprego. precarização do trabalho e fragilização do movimento sindical e social como um todo. Justiça ambiental. mais que uma expressão do campo do direito. assume-se como campo de reflexão. mobilizaçào e bandeira de luta de diversos sujeitos e entidades. como sindicatos. associaçoes de moradores. grupos de afetados por diversos riscos (como as barragens e várias substâncias químicas), ambientalistas e cientistas.

As entidades que promoveran e participaram do Colóquio farão reuniòes para organizar a estrutura de funcionamento e as primeiras atividades da Rede. com base nos princípios acima descritos. Todos os que se sentirem de acordo com a proposta da Justiça Ambiental estào convidados a participar.

Contatos com a rede brasileira de justiça ambiental - RBJA:

brsusta lase.org.br selene (avm.uftibr ou seleneh a ar.microlink com.brT e 1 : (0XX2) - 2286-1441 


\section{Bibliografia sobre riscos-}

\section{algumas referências compiladas por Selene Herculano (GSO/ICHF - Universidade Federal Fluminense) e Magda Zanoni (Universidade Denis Diderot - Paris 7)}

\section{Risk bibliography - some references compiled by Selene Herculano (GSO/ICHF - Universidade Federal Fluminense) and Magda Zanoni (Universidade Denis Diderot - Paris 7)}

AUBERT. F; SYI VISSTRE. J.P. (Eds.). Confiance et rationalité. (Confiança e racionalidade) lirança. Dijon: Lidição francesa do INRA. coleçào "Les Colloques". 5-6 de maio de 1999. 326 p.

AMALBERTI, R.: FUCHS, C.; GILBERT, C. (Eds.). Risques, erreurs et défaillances. Approche interdisciplinaire. (Riscos. erros e insucessos. Enfoque interdisciplinar ) Paris: Edição francesa do Centro Nacional da Pesquisa Cientilica CNRS - Maison des sciences de l'Homme-Alpes, maio de 2001. $361 \mathrm{p}$.

BECK, U. La société du risque. (A sociedade do risco). Paris: Edição francesa Aubier, $2001.524 \mathrm{p}$.

BULlaRD, R. D. Dumping in Dixie: race, class and environmental quality. Boulder: Westview Press, 1990.

BULLARD, R. D. (Ed.). Confronting Environmental Racism: voices from the grassroots. Boston: South End Press, 1993.

CARTIER. S. Chronique d'un déluge annoncé : crise de la solidarité face aux risques naturels. (Crônica de um dilúvio anunciado:crise da solidaridade diante dos riscos naturais) [s.l]: Edição francesa Grasset. 2002. 350 p.

CAMACHO. D. (Ed.). Environmental injustices, political struggles: race, class and the environment. Durham/London: Duke University Press. 1998.

COLLINS, H.: PINCH. T. Les nouveaux Frankstein. Quand la sicence nous trahit. (Os novos Frankstein. Quando a ciência nos trai). Paris: Edição francesa Flammarion [199-].
COLLINSON. H. (Ed.). Green Guerrillas: environmental conflicts and initiatives in Latin America and the Caribbean. Montreal-New York-London: Black Rose Books, 1997.

DAUPHINE, $\Lambda$. Risques et catastrophes. Observer-SpatialiserCompreendre-Gérer. (Riscos e catástrofes. ObservarEspacialisar-Compreender-Gerir) Paris: Edição francesa Armand Colin. [19-1. 178 p. (U-Geographic).

FABER, D. (Ed.). The struggle for ecological democracy. New York-London: The Guilford Press, 1998.

FELICE, P. L'effet de serre. Un changement annoncé. (O efeito estufa. Uma mudança anunciada). Paris: Ediçao francesa L'Harmattan, 2001. Ecologie et agronomie appliquée. 178 p.

FREITAS. C. M. Acidentes químicos ampliados - incorporando a dimensão social nas análises de riscos. Rio de Janeiro, 1996. Tese (Doutorado)-ENSUP/FIOCRUZ.

GOULD, K.: SCHNAIBERG, A.: WEINBERG, A. Local Environmental Struggles: citizen activismin the tread mill of production. Cambridge: Cambridge University Press, 1996.

HERCULANO. S. et al. (Orgs.). Qualidade de vida e riscos ambientais. Niterói: EDUFF, [199?].

LFVINE, A. Love Canal: science, politics and people. Lexington. MA: Lexington Books, 1982.

MAZUR. A. $\wedge$ Hazardous Inquiry: the Rashomon effect at Love Canal. Cambridge/London: Harvard University Press. 1998. 
PERETTI-WATEL, P. La société du risque.(A sociedade do risco). Paris: Edição francesa La Découverte, 2001. 128 p. (Repères).

ROBERTS, J. T.; TOFFOLON-WEISS, M. Chronicles from the environmental justice frontline. Cambridge: Cambridge University Press, 2001.

ROY, A. Les experts face aux risques: le cas des plantes trangéniques. (Os expertos diante dos riscos: o caso das plantas transgênicas) M. Paris: Edição francesa PUF/Le Monde, [19-]. $285 \mathrm{p}$.
SZASZ, A. Ecopopulism, toxic waste and the movement for environmental justice. Minneapolis: University of Minnesota Press, 1994.

BRYANT, B. (Ed.). Environmental Justice: issues, policies and solutions. Washington: Island Press, 1995.

TAYLOR, B. R. (Ed.). Ecological resistance movements: the global emergence of radical and popular environmentalism. Albany: State University of New York, 1995. 